\title{
Development of a Fire Risk Assessment Software as an Evaluation Tool and as a Teaching Tool
}

\author{
Dušan Gavanski and Matija Sokola \\ Visoka Tehnicka Skola strukovnih studija u Novom Sadu, \\ Novi Sad, Serbia
}

gavanski@vtsns.edu.rs sokola@vtsns.edu.rs

\begin{abstract}
Fire and explosion hazards, with consequences to lives and property, are present in various technological processes. A number of methods for qualifying and/or quantifying the fire risk have been developed. This paper presents bespoke software developed for fire risk assessment for buildings in which people work. The software serves two aims - an electronic notepad/calculator/ reminder for fire assessment experts and a teaching tool for students on fire safety and occupational health and safety study programmes.
\end{abstract}

Keywords: software tool, matrix method, fire risk assessment, teaching.

\section{Introduction}

Fire is a process of uncontrolled burning which needs three conditions: presence of a flammable matter, an oxidator and an ignition source. Fire risk is a statistical probability of these three appearing at the same time, coupled with a possibility of their interaction with people, material resources and the environment. Around 50,000 people per annum die in fires and many of them didn't have to become victims of fire.

One of the instruments to reduce both losses of lives and/or damage to the property is to conduct fire risk assessments - it should help to identify all potential hazards of occurrence and development of a fire in the considered building. Over the years, a number of recognized fire risk assessment methods have been developed for different types of buildings (Kiš, 2002), such as:

- generic use

- EUROALARM method (The European Fire Alarm Manufacturers Association),

- AUVA (Allegemeine UnfallVersicherungsAnstalt),

- BG (BerufsGenossenschaften - the method of German professional engineers),

- Fire risk matrix method,

- industrial buildings

Material published as part of this publication, either on-line or in print, is copyrighted by the Informing Science Institute. Permission to make digital or paper copy of part or all of these works for personal or classroom use is granted without fee provided that the copies are not made or distributed for profit or commercial advantage AND that copies 1) bear this notice in full and 2) give the full citation on the first page. It is permissible to abstract these works so long as credit is given. To copy in all other cases or to republish or to post on a server or to redistribute to lists requires specific permission and payment of a fee. Contact HPublisher@InformingScience.orgH to request redistribution permission.
- SIA 81 (Schweizerischer Ingenieur und Architekten Verein),

- VKF 2007 (Vereinigung Kantonaler Feuerversicherungen)

- multi-storey residential buildings

- FRIM-MAB, Fire Risk Index Method)

Combining AUVA and BG methodologies for usage in assessing risks at the workplace has been reported in (Kiš, 2002), which gave us a motivation to 
combine methodologies and adjust them for estimation of occupational risks due to fire hazards (Gavanski et al., 2010). On the other hand, development of bespoke software for collecting very different data sets for estimation of risk at the workplace (Sokola et al., 2009) has proved very useful. The software tool from (Sokola et al., 2009) has been expanded so now it contains 18 steps of the procedure for occupational risk assessment and risk management. The software for fire risk assessment, presented in this paper, is a further extension, hence the numeration of the steps in the software, described in the next chapter, starts from step 19.

The paper presents a methodological approach of fire risk assessment, based on a newly-formed matrix method, further improved than the method in (Gavanski et al., 2010). With the aim of teaching this methodology to safety students, a software application was developed to serve as a learning tool. The same software can be also used as an electronic notepad to both wellexperienced and less-experienced assessors to gather all the necessary data and speed up the process of fire risk assessment.

\section{General Requirements and Features}

Many matrix methods of safety assessment are based on semi-quantitative and/or descriptive terms that eventually lead to some sort of risk ranking. However, the numbers used in the method presented here are fully relevant. This method has two steps based on two $5 \times 5$ matrices, where the input factors are:

- firstly, the exposure of workers to fire hazards and the fire risk from building (and its content) are combined in a matrix in order to produce the estimate of probability of fire occurrence;

- then, the probability of fire occurrence and the level of possible consequences are combined in the second matrix in order to give the estimate of fire risk.

To obtain the numbers needed for the above assessment steps, as well as to follow the developed methodology, the software tool needs to allow a wide range of features:

- entering and retrieving various types of data,

- checking/ticking certain pre-formatted boxes, counting the number of checked boxes and calculating the risk parameters from those,

- communication with the database,

- generating reports and summaries, both for viewing on the screen and for printing,

- rigidity to take the user through the steps of the prescribed procedure in correct order, and occasional flexibility to change this order.

A number of possible platforms, such as PHP, MySQL, JavaScript, Oracle, etc, could be used to produce this software tool, and the chosen platform is the Microsoft Office Access 2003. It is most widely available in Serbia, especially in the small and medium enterprises, who are one of the target groups for using this tool. Finally, the ease of designing the reports that be used as a document for risk assessment, was an important criterion for choosing the Microsoft Access.

The main menu, shown in Figure 1, appears when the software is started and offers the following options:

- list of buildings to be assessed, (in the top left corner of Figure 1)

- analysis of fire hazards stemming from the building and its content (19),

- analysis of the existing preventive fire safety measures in the object (20),

- the first fire risk assessment (21), 
- choice of additional preventive fire safety measures that can be installed in the object (22)

- consequent fire risk assessment (if/when the additional measures are installed, (23).

\section{SOFTWARE TOOL - FIRE PROTECTION}

\section{EXIT THE APPL.}

LIST OF OBJECTS

\section{MODULE 1}

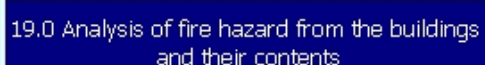

and their contents

20.0 Analysis of existing preventive fire safety measures in the building

21.0 The first fire risk assessment

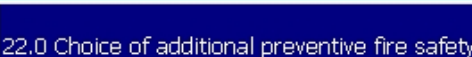

measures that can be installed in the building

23.0 Consequent fire risk assessment

Figure 1: Programme panel - the main menu.

\section{Risk Assessment Phases and Steps}

At the very beginning, the assessor forms a list of all buildings in a factory and enters the names of participants in the assessment - responsible persons from company and assessors.

The first phase (step 19) gives a check-list with 15 questions necessary for the initial analysis of fire hazards from the building itself as well as from its content. The assessors must choose the answer from the drop-down menu containing "safe", "unsafe" or "irrelevant", but also have the flexibility to type in comments, as shown in Figure 2. There is also a very important option - to print a report with all the questions, answers and comments after this step is completed.

The second phase (step 20) is similar to the phase 1, but contains a check-list of 17 questions, aimed to collect data regarding the existing preventive measures of fire safety in a building.

The third phase (step 21), the first assessment of fire risk, is split into 5 sub-steps:

1. a numerical value of fire hazard is calculated on the basis of the qualitative checklist of phase 1 (here chosen as a linear ratio of "safe" vs. relevant (safe and unsafe) answers) and a quantitative rank from 1 to 5 is assigned to the fire hazard. At the same time, the type of corrective actions is suggested in a descriptive way, as shown in Figure 2.

2. the exposure to fire hazard is selected by the assessor, in one of the three possible ways: numerical value - presence in the building during the working day as the percentage of time in steps of $20 \%$, the qualitative descriptor (very rare, occasional, frequent, dominant and continuous) and the quantitative rank - from 1 to 5 .

3. the fire hazard rank is combined with exposure frequency level in a $5 \times 5$ matrix, whose result is then scaled to 5 ranks of probability of fire occurrence, as shown in Figure 3. 
4. an automatic processing of the Phase 2 checklist gives a numerical value ( 0 to $100 \%$ ), the qualitative descriptor (negligible, minor, moderate, large, severe) and the qualitative rank (1 to 5) of the severity of possible fire consequences.

\subsection{THE FIRST ASSESSMENT OF FIRE RISK}

\begin{tabular}{|c|c|}
\hline Main menu & List of buildings \\
\hline Previous menu & Next menu \\
\hline
\end{tabular}

\begin{tabular}{l|l} 
Building name & Woodworking shop \\
\hline
\end{tabular}

\subsection{Fire risk from the object and its content}

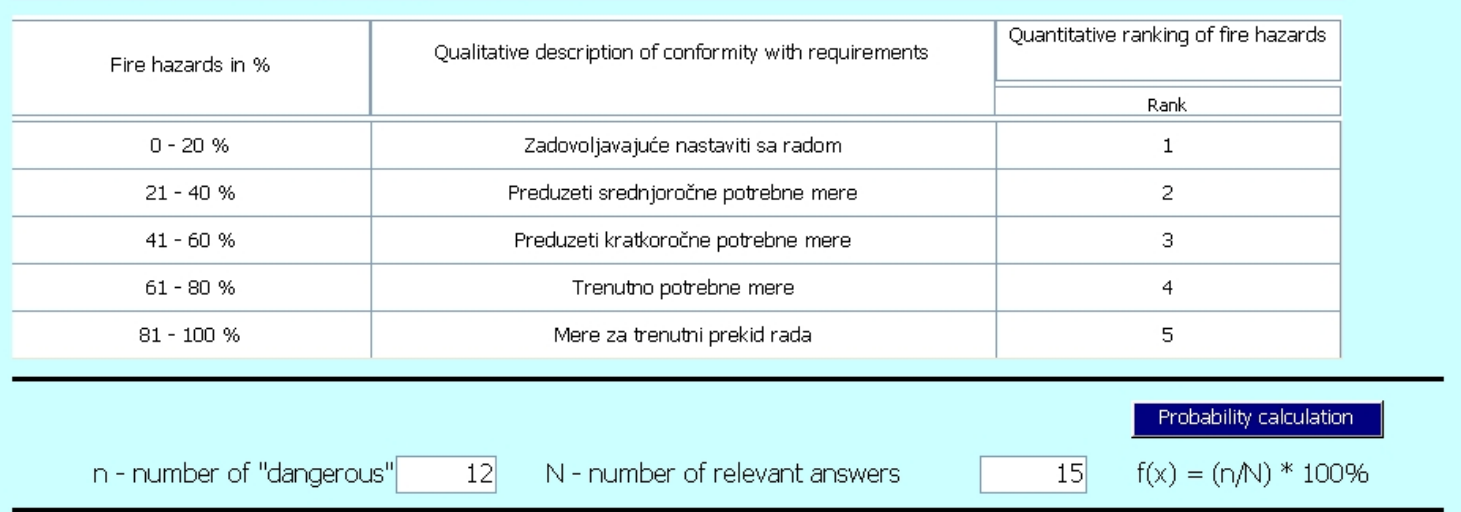

\section{The first assessment}

Fire hazards in \%

Qualitative description

Quantitative ranking

$80 \%$

Figure 2: Programme panel - fire risk from the building and its content, the first assessment.

\begin{tabular}{|c|c|c|c|c|c|}
\hline \multicolumn{5}{|c|}{ Numerical value of fire occurence probability } & 8 \\
\hline \multicolumn{5}{|c|}{ Rank of fire occurance possibility } & 3 \\
\hline \multicolumn{4}{|c|}{$\begin{array}{l}\text { Result of the assessment, from the } \\
\text { matrix }\end{array}$} & $\begin{array}{l}\text { Qualiative description of the fire } \\
\text { occurance possibility }\end{array}$ & Quantitative rank of the fire occurance \\
\hline \multicolumn{4}{|c|}{1,2} & Improbable & 1 \\
\hline \multicolumn{4}{|c|}{$3,4,5$} & Possible & 2 \\
\hline \multicolumn{4}{|c|}{$6,8,9$} & Very probable & 3 \\
\hline \multirow{2}{*}{\multicolumn{4}{|c|}{$\frac{10,12,15,16}{20,25}$}} & Likdy & 4 \\
\hline & \multicolumn{2}{|c|}{20,25} & & Very likely & 5 \\
\hline First & Previous & Next & Last & Building & \\
\hline
\end{tabular}

Figure 3: Programme panel - probability of fire occurrence, the first assessment. 


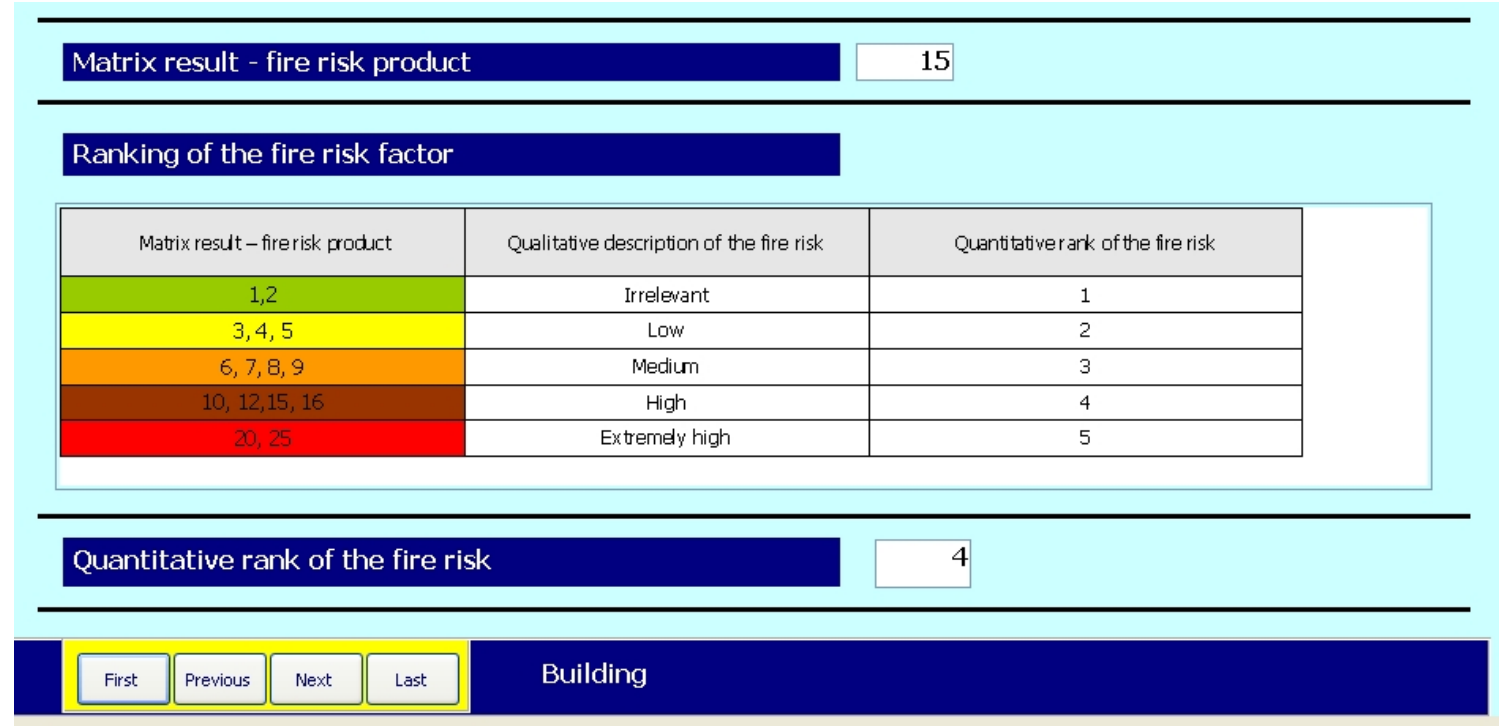

Figure 4: Programme panel - fire probability matrix and fire risk ranking, the first assessment.

5. the rank of fire consequences is combined with the probability of fire occurrence and the rank of fire risk is obtained, as shown in Figure 4.

Now the iterative part of the assessment process can be initiated - in the fourth phase (step 22) a new feature of the fire hazard can be added or removed and/or a preventive measure can be virtually installed by changing some answers in the checklists of phases 1 and 2 . There is a difference from phase 1 that instead of comments there is a field for entering the description of the chosen preventive measure.

Then, in the fifth phase, (step 23) the new level of fire risk is calculated by the procedure same as in phase 3.

\section{Considering the Users}

From the outset, the main feature was to be an easy use of the software tool, for fire risk assessors and students alike.

By giving the quantitative, qualitative and descriptive ranking of every parameter during the assessment process, the software is constantly warning/reminding the assessor of the value of the parameters. When used as a teaching tool, this feature can be used by the lecturer to remind students to observe the values/ranks of every parameter in the process and note the high-risk dimensions from early stages of the assessment process.

The second important feature is the iterative process that can be used as an extrapolator for an estimate of possible risk reductions in several modalities:

- adding a new fire safety measure - if we install a sprinkler system, by how much the fire risk would be reduced?

- removing some of the dangers from the building and its content - if the storage of paints and solvents is removed from the building, would it reduce the fire risk ?

- if the workers spend less time in certain parts of the building, will it reduce the risk?

- if controlled access is introduced in some rooms/buildings, are the risks reduced ? 
Such "what if" feature provides a quick estimation of the effects of possible risk reduction measures and helps users/students to identify which measures will be more effective than others.

\section{Conclusion}

The paper presents a software tool that helps the risk assessors to identify and note fire hazards at the workplace and to provide an estimate of the fire risk, as a part of the occupational risk assessment process. The developed software tool reminds the user not to omit something that may be important for the assessment process and offers the option to print the entered findings for documentation purposes. By providing the iterative process, the software gives a very quick analysis of the efficacy of the possible preventive fire safety measures.

The software is also an excellent learning tool, used for teaching the fire safety students in the School. It provides a vehicle for teaching the students that a large number of detailed data needs to be collected and presents them one possible methodology for processing the collected data into a quantitative fire risk value.

\section{References}

Gavanski, D., Milanko, V., \& Krnjetin, S. (2010). Procena požarnog rizika u stolarskoj radionici na osnovu ček-liste i matrice rizika [Assessment of fire risk in a woodworking workshop based on check-lists and risk matrix], Proceedings of the 2nd International conference on Safety Engineering and 12th International Conference on Fire and Explosion Protection, pp.11-20., Novi Sad, Serbia (in Serbian).

Kiš, D. (2002). Znanstveni pristup analizi rizika radnog mjesta u procjeni opasnosti [Scientific approach to analysis of the risk at the workplace in hayard assessment], Rad Sigur. 6, 2002, pp.235-253, ISSN 0352-36775 (in Croatian).

OSHA - European Agency for Safety and Health at Work, (2006). Risk Assessment Tool, Document No. TE-76-01-001-EN-C.

Sokola, M., Gavanski, D., \& Bukta, Z. (2009). "Pro-Check Hazard" software tool for hazards/harms identification for risks assessments at the workplace and in the work environment, Proceedings of the 1st International Conference on Information Society and Information Technology ISIT 2009, Dolenjske Toplice, Novo Mesto, Slovenia, October 2009.

\section{Biographies}

Dušan Gavanski obtained his MSc. in mechanical engineering in 2003 and is now a $\mathrm{PhD}$ candidate, both at the University of Novi Sad, Serbia. He joined the School of higher professional technical education in Novi Sad, Serbia, in 2002, where he is currently a lecturer. His research and professional interests encompass fire safety and occupational health and safety.

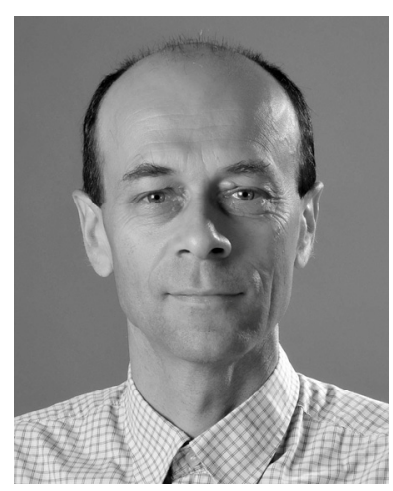

Matija Sokola completed his $\mathrm{PhD}$ at Liverpoool John Moores University, UK, in 1998. He was an instructor at the University of Bath, UK until 2007, when he joined The School of higher professional technical education in Novi Sad, Serbia where he is a Professor of vocational studies and a Head of electrical engineering department. His research and professional interest are wide - from control of electric drives and electronic power converters, via metrology, to the occupational health and safety. 